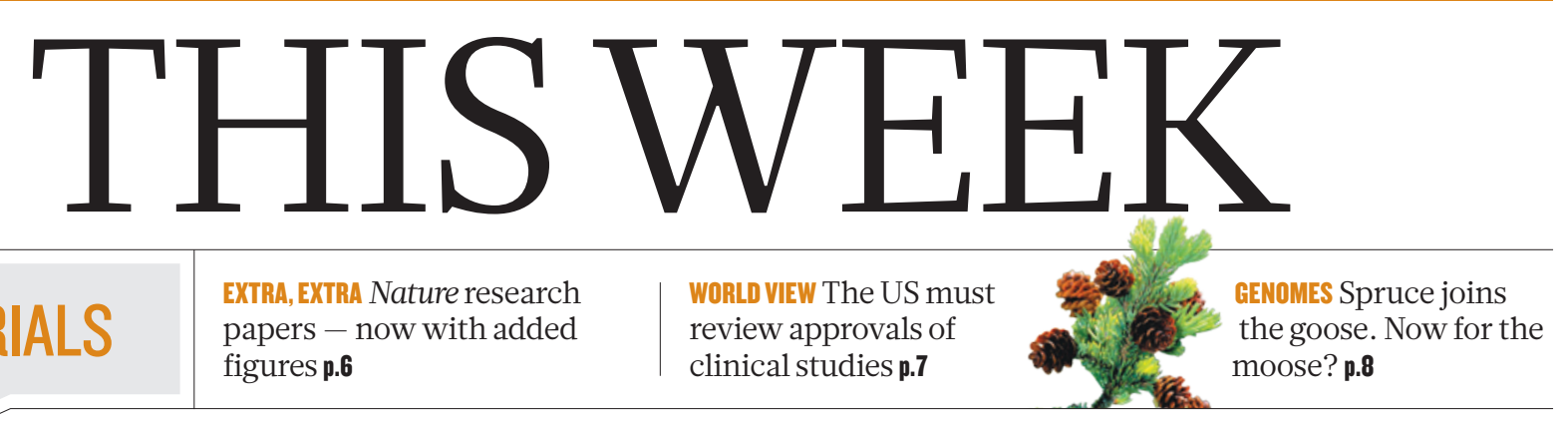

EDITORIALS figures $\mathbf{p . 6}$
WORLD VIEW The US must clinical studies $\mathbf{p . 7}$ the goose. Now for the moose? p.8

\title{
The paper trail
}

\section{Scientists must embrace funding-agency efforts to track research outputs and encourage} open access to the literature.

$\mathrm{L}$ ast week, the world's research-funding agencies signalled a welcome desire for wider access to published papers. The Global Research Council, a voluntary discussion forum that takes input from hundreds of funding agencies in regional meetings around the globe, released an action plan for promoting open access - although specific policies are left up to individual agencies (go.nature.com/ gonk6w).

Scientists need this top-down push. Individually, they have proved reluctant to make their papers freely available, despite the determined efforts of open-access campaigners. For example, although the Wellcome Trust in London, one of the world's biggest biomedical research charities, has since 2005 provided an open-access mandate and the money to support it, by last June only $55 \%$ of the research papers that it funded were open access. Most of those had been uploaded into repositories by publishers, rather than by researchers.

The Global Research Council discussions and action plan have made it clear that when push comes to shove, most agencies lack the will to fund 'gold' open access - in which the author pays for a paper to be free to access as soon as it is published. The UK funding councils, which all provide money towards gold open access, are notable exceptions. Others, such as agencies in the United States, have little money to spare, and are agreeing to wait for publishers or authors to make the results of research freely available six months or a year after publication - 'green' open access. Germany has a dual system, in which researchers can apply for funds to make papers immediately available, but universities can also apply for pots of money expressly to support open access. In Brazil, a system whereby the government negotiates with publishers for open access on a national level is being considered. The permutations are endless.

There is no consensus on whether funding agencies should merely encourage researchers to make their work open (through either green or gold routes), or should actively monitor progress and provide sanctions - such as refusing future grants - for non-compliance. To some extent, reluctance to enforce mandates comes from a desire to ease scientists into open access slowly, but it can also signal endorsement of the idea that agencies should just give researchers opportunities and support for open access, ultimately leaving scientists the freedom to do what they want with their papers.

There is one thing on which funding agencies agree, however. To monitor whether open-access mandates are effective, and to share information on those that are, agencies need to track the outputs of their funding better. At the moment, only a few funders, mainly medical ones - such as the UK Medical Research Council, the Wellcome Trust and the US National Institutes of Health - can give a figure for the proportion of papers resulting from their funding that are open access.

So publishers and funding agencies alike are jumping at new ways to track the sources of funding for published scholarly research. In the same week as the Global Research Council released its action plan,

the non-profit publisher alliance CrossRef launched a service called FundRef (www.crossref.org/fundref). The initiative provides a standardized way to report funding sources for published research, by adding them to the metadata on online research papers.

In the United Kingdom, funding agencies expect researchers to provide extensive details on the results of their funding through

"To monitor

whether open-

access mandates

are effective,

agencies need

to track the

outputs of their

funding." mechositories through mechanisms such as re3data.org, a registry of repositories. At the same time, the ORCID system provides unique identifying numbers to track individual researchers' work, and services such as Figshare are helping to make other types of output, such as data, recognizable and citable.

All this means that as funding agencies push for open access, researchers will need to have their outputs tracked as never before. They should embrace this as a chance both to show off their publications and to acknowledge the support networks that fund their work.

\section{Moral authority}

Research must be seen to be accountable, even if that means hanging on to redundant reviews.

A ll scientists must contend with regulation and bureaucracy, despite their frequent complaints that such processes stifle and slow their work. US researchers in gene therapy perhaps feel the pressure of red tape more than most. Is now the right time to ease that burden?

The US Institute of Medicine wants to find out. This week, it kicked off a review of an oversight committee that many in gene therapy argue is redundant. They might be right, but when it comes to medical ethics, it is not enough for scientists to do the right thing - they must also be seen to do so.

The Recombinant DNA Advisory Committee (RAC) was set up within the National Institutes of Health (NIH) in 1974 as a direct response to public concerns about the ethics and safety of research involving lab-assembled DNA sequences. After devising guidelines 